\title{
Da leitura do mundo à leitura da palavra’
}

From reading the world to reading the word - a testimony-interview by Paulo Freire

https://doi.org/10.34112/2317-0972a2021V39n83p21-29

\section{ALB}

Paulo Freire abriu de maneira maravilhosa e significativa o $3^{\circ}$ COLE, COM UMA conferência sobre a importância do ato de ler. Nesta entrevista, a partir de algumas questões colocadas pela ALB e expressas pelo Prof. Ezequiel Theodoro da Silva, Paulo Freire especifica algumas de suas afirmações e fala da sua reaprendizagem da realidade brasileira.

Ezequiel - Paulo, antes de colocar algumas questões sobre as suas ideias e projetos, com base na sua vontade e ao sabor deste momento, expresse alguns tópicos significativos de sua experiência na área da leitura, que possam também ser significativos àqueles que ensinam leitura.

Paulo - Muito bem, como é que eu me arrumo agora para responder? Em primeiro lugar, eu gostaria de dizer nesta entrevista que estou me sentindo muito à vontade pelo próprio tom com que a entrevista começou, pelo próprio estilo da pergunta feita. Me deixa assim muito à vontade mesmo. E é nesse estar à vontade que eu vou tentar agarrar a pergunta e fazê-la de novo a mim mesmo. Na verdade, parte desta pergunta eu me faço muito constantemente - eu sempre levei muito a sério a leitura e pra mim

1. Entrevista-depoimento inicialmente publicada em Leitura: Teoria \& Prática, Campinas, São Paulo, v. o1, n. o, p. 03-09, novembro/1982. Foi o texto de abertura da nossa LTP. 
é muito importante que se comece esta entrevista comigo com uma pergunta como essa. E eu não sei se a esta altura eu já não estou desvirtuando, mudando um pouco a própria pergunta, mas não faz mal que eu o faça. É bom, eu dizia, porque às vezes eu tenho impressão, Ezequiel, de que eu não sou compreendido bem - quando, por exemplo, eu critico o que eu costumo chamar de "compreensão mágica da palavra escrita" e que se expressa através de atitudes nossas, intelectuais, diante de livros, de textos: de textos pra ler e de textos pra escrever. Por exemplo, o aspecto mágico da palavra que se expressa na leitura quantitativa: quanto mais livro eu compro, quanto mais livro eu olho, quanto mais livro eu penso que estou lendo, tanto mais eu estou sabendo. Ou então quando eu critico o mesmo caráter mágico ou compreensão mágica da palavra escrita, quando eu tenho que escrever, por exemplo, e me preocupo se o texto que eu estou escrevendo vai ter 150 páginas e eu só sou capaz de escrever 10. Morro de vergonha - o que é que os meus companheiros de academia vão dizer se aparece um artigo meu com 10 páginas... Bem, eu volto a dizer, pra mim é ótimo que se comece uma conversa assim. Eu gostaria de dizer que, quando eu faço essa crítica, ela é muito mais uma advertência a mim também, mas essa crítica não significa, de maneira nenhuma, que haja nela uma espécie assim de repouso na irresponsabilidade; quer dizer, uma espécie de fuga da seriedade. Não, eu acho que tanto os estudantes quanto nós, os professores, temos de ler mesmo; temos de ler seriamente, mas LER, isto é, temos de nos adentrar nos textos, compreendendo-os na sua relação dialética com seus contextos e o nosso contexto. O contexto do escritor e o contexto do leitor, quando eu leio um texto. Portanto, a minha crítica, quando por exemplo eu, como professor, me recuso a sugerir uma relação bibliográfica de 40 livros, 50 livros, 60 livros, não é que com isso eu sugira ao estudante que ele não leia, de maneira nenhuma. No texto que eu escrevi para o Congresso de Leitura que você coordenou e que tinha 11 páginas (não mais do que isso e já foi muito até e deu uma hora de leitura), eu falava, por exemplo, em alguns desses momentos de minha experiência em que a importância da leitura veio afirmando-se ou constituindo-se em mim, mas de uma leitura que eu encaro como um trabalho sério, penoso, às vezes. Por exemplo, eu não sei das vezes em que eu levo uma hora, uma hora e meia numa página e durmo depois em absoluta paz porque só consegui ler, naquela noite, uma página. Agora, aquela página eu li mesmo, eu a entendi. Evidentemente que é possível que se você lesse a mesma página pudesse até entendê-la, ganhar a inteligência dela mais rapidamente do que eu, pois há " $n$ " fatores relacionados com uma competência específica, que podem diminuir o tempo de inteligência de uma página. Mas, a pergunta coloca o que é que eu... 
“... eu não leio para formar-me; eu me formo também lendo..."

Ezequiel - Alguns tópicos que você considera significativos àqueles que ensinam leitura.

Paulo - Eu acho que é isso mesmo: a minha experiência me veio ensinando que a seriedade $d a$ leitura e na leitura é absolutamente fundamental. É engraçado... eu não leio para formar-me; eu me formo também lendo, entende? É essa a posição. Mas, por outro lado, eu não cerro as portas na leitura da palavra porque eu acho que ela não se dá, em termos profundos, sem a leitura do mundo.

Ezequiel - Na abertura do $3^{\circ} \mathrm{COLE}$, você afirmou que "a leitura do mundo precede a leitura da palavra". Sem tender para o "receitismo", gostaríamos de saber, Paulo, se você poderia estabelecer algumas formas de encaminhar o processo de leitura do mundo, principalmente nos limites de uma sala de aula de uma escola pública.

Paulo - Ahhh!!! (de surpresa e contentamento)

Ezequiel - E se você vê possibilidade de se encaminhar esse tipo de leitura na escola pública...

Paulo - Mas é claro que eu vejo, e eu acho que seria de fundamental importância. Na sala de aula, nos limites de uma sala de aula, na geografia da sala de aula, o que se poderia e o que se deveria fazer, no meu entender, já era a concomitância das duas leituras, isto é, já era a leitura do mundo juntamente com a leitura da palavra referida ao mundo. Não creio que isso seria difícil. Inclusive, uma atividade primeira da criança - vamos considerar uma criança de escola primária - para a qual a educadora sugere, por exemplo, que fale um pouco de como caminhou de sua casa para a escola. Quer dizer, que cada criança ou grupo de crianças fizesse o discurso da sua rua ou o discurso sobre a sua rua, contando o que viu, o que não viu, escrevendo, afinal de contas - porque (...). Há uma diferença entre "andar", tomando o "andar" sentindo a rua e "andar" percebendo a rua - quer dizer: a percepção crítica implica, na verdade, a apreensão daquilo que é sentido e uma compreensão da razão de ser do que sente. Então, num primeiro momento, a criança ia fazer a descrição do visto, do sentido, das coisas que foram tocadas pela visão, pela audição. E, através de exercícios como esse, as crianças começariam uma tentativa de compreensão dessa realidade - isso, no fundo, já é uma leitura parcial. Aí seria mais uma leitura da geografia do percurso. Daí a pouco, essa leitura poderia dar o salto para a sociologia do percurso, para a política do percurso. Ora, a partir da oralidade, é possível chegar à escrita e, então, você faz a leitura oral do mundo, depois você faz a escrita 
da palavra com que você leu o mundo e você lê a palavra que escreveu. No meu entender, inclusive, esse poderia ser um momento extraordinário para discutir com a criança - por exemplo, de crianças de áreas proletárias ou de áreas populares - $\mathrm{o}$ que é certo e o que não é certo, isto é, qual é a utilização que tu tens de falar, de dizer o que é certo é "nós chegamos" e não "nós cheguemo". A professora que saiu desta sala agorinha mesmo está fazendo um trabalho exatamente nessa linha: de mostrar à criança que o chamado "padrão culto" existe e que a criança precisa aprender esse padrão, mas que ele não é superior ao chamado "padrão popular", utilizado pela criança. Ora, então eu acho, Ezequiel, que, através das estórias que as crianças contam e que as crianças ouvem, através das descrições que as crianças façam do seu bairro, da sua área, da sua favela, a gente poderia trazer para dentro da escola uma leitura do mundo, mesmo no seu aspecto mais geográfico, e depois saltar para a compreensão social dessa leitura, ao lado da leitura da palavra.

\section{“... Gramscifoi, sobretudo, um italiano."}

Ezequiel - Bom, eu acho que a outra pergunta tem muita relação com aquilo que você está dizendo. Diz assim: Em termos da leitura da palavra, você parece privilegiar um tipo de texto a ser colocado ao leitor - aquele que expresse a sua realidade existencial imediata. Paulo, queríamos saber como se faz a passagem desse tipo de texto (geralmente produzido pelo próprio aluno ou pelo educador) para outros tipos de texto, encontrados na nossa realidade social (isto é, escritos por outros autores).

Paulo - Eu acho que é absolutamente necessário, se a gente agora fala de formação científica, rigorosa, que o estudante caminhe, na sua trajetória, na sua escolaridade, com uma convivência com o que eu chamaria de "clássicos", neste ou naquele campo. Mas, o que me parece absolutamente necessário é que a própria leitura de um autor (que esteja distante, por exemplo, sociológica e culturalmente e até historicamente), que o leitor tenha a compreensão crítica do contexto do autor do texto. É isso que eu quis dizer: no fundo um esforço, eu acho, do leitor de, diante de um texto, localizar o contexto do autor do texto e compreendê-lo. Fazer a leitura daquele texto em relação ao seu contexto. Não sei se está claro... No fundo, é uma espécie assim de triangulação: o contexto de Gramsci... eu não posso ler Gramsci, nem devo ler Gramsci, simplesmente porque fui à livraria e comprei um livro dele; mas, ao ler Gramsci, eu preciso estar informando-me do contexto social, político, ideológico, histórico de Gramsci. Eu tenho de situar Gramsci num determinado tempo: Gramsci não adivinhou as coisas - quando 
Gramsci escreveu, ele tinha... Gramsci foi, sobretudo, um italiano. Isso não significa que Gramsci não é útil ao brasileiro ou ao norte-americano, pelo contrário... Mas eu acho fundamental este aspecto e é isto que eu estava querendo deixar claro: quando eu leio Gramsci, eu preciso ir-me inteirando do contexto de Gramsci, em que aquele texto se constituiu. Mas agora eu preciso também de um outro esforço: de como relacionar o texto de Gramsci com o meu contexto. $\mathrm{O}$ meu contexto histórico, social, político não é o de Gramsci, mas isso não significa que Gramsci não tenha muito a me ensinar. Ele tem, mas o que é preciso é ter clara essa relação entre o contexto do autor e o contexto do leitor. É preciso colocar o texto nessa encruzilhada ou nessa mediação. Por exemplo, no ano passado eu fiz uma leitura com um grupo de estudantes de pós-graduação, de 5 páginas. $\mathrm{O}$ texto era de um camponês, do Ciço, que o Carlos Rodrigues Brandão entrevistou e pôs essas 5 páginas como prefácio de um dos seus livros. Para você ter uma ideia de como eu levo a sério esse negócio da leitura, para ler essas 5 páginas. Quer dizer, nós fizemos uma análise, durante 12 horas, de 5 páginas. Então, o que a gente descobriu aí foi uma coisa extraordinária. Depois da leitura desse "Ciço" (o grande filósofo Ciço...), eu então sugeri aos estudantes uma leitura do Gramsci. Daí o que é que acontece? O sujeito leu o Ciço, entendeu o Ciço, discutiu o Ciço, foi a Gramsci e, lendo Gramsci, entendeu o Ciço melhor depois. É esse movimento de ida e volta; eu acho que essa passagem se dá de forma muito dinâmica e não mecânica. E pra mim, de novo, o problema não é quantitativo. $O$ que me preocupa não é chegar aqui e dizer: Ezequiel, em 82 eu li 1.200 páginas, mas é saber exatamente o que é que eu fui capaz de fazer em termos de leitura do real, do concreto... compreensão da história, mesmo quando não há palavra nenhuma. Como é que sou capaz de entender o fato citado ali, através da notícia da televisão, do rádio, etc... através do programa de humor, da propaganda comercial e não exclusivamente através do livro.

"Não vejo por que não estimular a escrita também."

Ezequiel - Eu vou pegar essa "deixa” para lhe fazer a questão seguinte. Paulo, alguns teóricos chegaram a prever a morte da alfabetização em língua escrita, dizendo que devemos alfabetizar as crianças para a compreensão de outros tipos de linguagem. Queremos saber a sua posição frente a tal afirmação.

Paulo - Bem, em primeiro lugar, eu acho que reduzir a comunicação puramente pra linguagem escrita, e até mesmo oral, é estreitar a capacidade comunicante do ser humano. Eu tenho um amigo na Universidade de Costa Rica, o Prof. Francisco 
Gutiérrez, que vem desenvolvendo, há dez anos, o que ele chama de "linguagem total", seguindo uma certa linha de um filósofo francês, cujo nome me escapa neste momento. Ora, eu sou muito amigo do Gutiérrez e, portanto, eu acho que não podemos reduzir isso. Agora, por outro lado, eu não acredito que a linguagem escrita vá desaparecer tão cedo; eu acho que a oralidade foi por onde o ser humano começou e essa tende a crescer e é até necessário estimular a expressividade oral das crianças, etc... Não vejo por que não estimular a escrita também. Também não vejo como cercear ou minimizar outro tipo de comunicação.

Ezequiel - Nas suas andanças por este nosso Brasil, tendo por objetivo cumprir o seu trabalho de reaprendizagem da realidade brasileira, gostaríamos de saber como você sente o "clima" da alfabetização e da leitura. Quais os projetos nacionais, desenvolvidos ou em desenvolvimento, que mais o "assanharam"?

Paulo - Ora, eu não teria muito o que dizer disso. Simplesmente, eu gostaria de te dizer que uma das coisas que me alegraram na minha volta ao Brasil, por exemplo, foi o encontro com gente como tu e quando aqui eu me refiro a ti pessoalmente eu encarno em ti toda essa geração de que tu fazes parte e que está sendo capaz de levar a efeito um Encontro como esse que tivemos no ano passado, que juntou aqui o Brasil todinho com uma quantidade enorme de gente preocupada exatamente com a leitura. Eu não sei se tu te lembras de como eu expressei essa minha satisfação. Essa preocupação pela leitura, os livros que eu tenho encontrado, a bibliografia sobre isso, hoje no Brasil... a preocupação com os estudos linguísticos, como cresceu isso tudo! Imagine como eu me sinto contente nas minhas relações com o Instituto de Linguística da UNICAMP. Isso tudo tem-me dado uma grande alegria; eu acho que cabe a... E eu me centraria em tudo isso e deixaria aqui de me referir a um ou outro caso, a um ou outro exemplo de experiência em alfabetização de adulto, etc... Pra mim, o mais fundamental é toda essa preocupação que eu tenho encontrado no campo da leitura e uma compreensão crítica do ato de ler; não de uma leitura puramente mecânica. E os problemas relacionados ou vinculados com a linguagem popular, em contraposição à chamada linguagem erudita; o respeito pelas formas populares de expressão. Isso tudo tem, como tu disseste, me "assanhado" bastante.

Ezequiel - Finalmente, Paulo, nós gostaríamos de saber alguma coisa sobre você, enquanto leitor da palavra. Diga pra gente o que você está lendo neste momento da sua vida e a sua forma de ler um texto.

Paulo - Olha, no momento eu estou fazendo umas leituras... por exemplo, Gramsci. Gramsci é uma das minhas leituras, uma das minhas preocupações. 
Lukacs, Habermas, os pensadores marxistas norte-americanos da nova ou da esquerda norte-americana, muito dialéticos, nada mecanicistas são tipos de leitura que me preocupam muito. Agora, tu me perguntas como...

Ezequiel - Antes disso, literatura, você tem lido alguma coisa?

Paulo - Literatura, eu te confesso que depois que cheguei eu não pude ainda, mas... porque eu tive... eu continuo defasado nos dois anos e meses de minha volta. Eu continuo defasado porque encontrei uma quantidade enorme de trabalhos publicados no Brasil, inclusive de 10 anos pra cá, de que eu não tinha sequer notícia. E eu não tive tempo ainda e te confesso que a mim me dói. Eu não estou a par de ninguém; eu não li ainda nenhum novo romancista brasileiro, novelista, poeta, desde que cheguei. É uma coisa que a mim me dói, mas na verdade eu não pude fazer ainda - porque, inclusive, eu tenho escrito muito também. Agora, tu perguntas como é que eu...

\section{“... um dos princípios fundamentais para ler é aceitar que não se entendeu o que se leu."}

Ezequiel - Veja bem, Paulo, como é que você seleciona um texto, como é que você vai ao texto. Isso aí eu acho que é importante.

Paulo - Eu vou ao texto carinhosamente... Em segundo lugar, de modo geral, simbolicamente, busco a convivência com o texto. Porque na verdade... De modo geral, simbolicamente, eu ponho uma cadeira e convido o autor, não importa qual, a travar um diálogo comigo. $\mathrm{O}$ que equivale a dizer: eu vou lendo o texto e vou fazendo perguntas ao autor e a mim mesmo. Quer dizer: eu vou me perguntando em torno, por quê. Nesse hábito de perguntar é que eu vou, em certo sentido, decifrando ou decodificando o texto. Períodos, ou melhor, uma certa nucleação temática do livro. Mas, num primeiro momento, eu vou fazendo perguntas a mim mesmo e vou fazendo simples sublinhamentos nesses prováveis núcleos temáticos, que eu vou surpreendendo, que eu vou descobrindo. Vamos admitir que eu faço isso no decorrer de um capítulo, se se trata de um livro por exemplo; terminada a leitura primeira de um capítulo, eu dou uma volta (por isso que eu demoro muito pra ler...), eu volto ao primeiro capítulo e vou agora, sobretudo, enfatizando pra mim a leitura daquilo que eu grifei. E às vezes ocorre que, por causa disso, eu paro de ler porque daí eu escrevo uma página, duas... Eu me sinto desafiado durante o processo da leitura daquelas dez páginas e esse desafio, provoca em mim a redação de alguma coisa que, aparentemente, não teria nada que ver com aquilo que eu li, mas na verdade nasceu daquilo. Às vezes, é uma palavra 
que me sugere uma reflexão maior; às vezes, isso não ocorre e então eu faço as minhas notas, etc... redijo no pé da página e prossiga a leitura. Às vezes (e isso é uma coisa que eu sempre sugiro também, mas agora está meio difícil fazer porque eu estou muito desorganizado), eu saio... vamos admitir que estou lendo Gramsci e, em certo momento eu largo Gramsci e faço então leituras simultâneas em função do mesmo tema e em autores diferentes, mas mais ou menos relacionados e às vezes até em posições diferentes ou contraditórias, etc... A leitura, então, de um texto, pra mim, às vezes me conduz à leitura de outros textos, simultaneamente. Agora, como eu já te disse antes, não me preocupa muito a estatística das páginas: nem das páginas que eu leio, nem das páginas que eu escrevo, entende? Se eu sou capaz de ler 10 páginas no mês, é porque eu só pude ler 10, mas eu fiz força para ler as 10, eu não estou chutando, eu me sinto sério com a leitura das 10. Em última análise, então, eu diria que eu me aproximo de um texto carinhosamente, eu me aproximo de um texto com seriedade e respeito ao texto e ao autor do texto e, quando eu não entendo, eu não tenho raiva do autor, entende? Eu procuro me capacitar melhor pra entender melhor. Eu me lembro, por exemplo, da guerra que eu tive comigo mesmo quando eu li pela primeira vez - e não tenho vergonha nenhuma de dizer isso, inclusive aos estudantes nos seminários - "A Dialética do Concreto", do Kosik. Eu li dez vezes o Kosik, já. (...) Depois de um incidente ocorrido comigo em Genebra, em que eu parecia me sujeitar à domesticação da cotidianeidade, sugeri aos alunos que lêssemos um capítulo do Kosik. Capítulo em que ele analisa a alienação do cotidiano. E eu disse o seguinte: Olha, faça o seguinte, cada um lê em casa e vamos depois discutir aqui; todo mundo traz o seu texto que a gente lê aqui, junto. E no dia da outra sessão, tava todo mundo em situação dificílima e toda a juventudezinha dizendo a mim assim: Olha, Prof. Paulo, nós não entendemos coisa nenhuma disto aqui... E eu disse assim: vamos ler juntos. Começamos a ler e, quando lemos o primeiro período, ninguém entendia e tinha uma menina quase chorando e eu disse: Não se preocupe não porque eu também não entendi e vamos agora tentar, juntos, entender. Quer dizer, eu acho inclusive, Ezequiel, que isso também é, pra fechar o nosso papo, do ponto de vista da leitura (porque há também uma espécie assim de sabedoria do fazer a leitura, que você obtém fazendo a leitura)... Isto é: você não ensina propriamente a ler, a não ser que o outro leia, mas o que você pode é testemunhar ao aluno como você lê e o seu testemunho é eminentemente pedagógico. Então, eu tenho a impressão e tenho feito essa experiência no Brasil, depois da minha volta - fiz no estrangeiro, fiz nos Estados Unidos, fiz na Europa - tenho a impressão de que ler COM o estudante, com os estudantes é também importante. Só que a gente corre riscos... 
que às vezes alguns de nós, professores, não quer correr. É o risco de numa leitura, em certo momento numa leitura geral de um texto, cuja totalidade você percebeu, como professor você é capaz de discutir, você passeia em cima daquele texto, mas há um certo momento da totalidade daquele texto em que você não entrou, que você não conseguiu apanhar. Então, o risco que você tem de ler junto com os estudantes é que coincida que um estudante também não entrou, naquele momento, e, como ele estava aprendendo a ser curioso, ele para e diz: Olha, Paulo, eu não entendi isso aí! $\mathrm{E}$ o risco da gente, que a gente às vezes não quer correr, é um risco tão simples de ter a coragem de dizer que também não entendeu. Então, eu acho que um dos princípios fundamentais para ler é aceitar que não se entendeu o que se leu...

Ezequiel - É... veja você como isso que você disse "chacoalha” com o próprio autoritarismo que a gente vê no ensino da leitura, com o professor tendo a chave da interpretação, o professor tendo a chave da interpretação de uma forma impositiva, dogmática, de modo a fazer o aluno reproduzir a interpretação "certa”.

Paulo - Exato. E eu acho que a melhor coisa a fazer agora é fechar a entrevista com as tuas palavras. Porque no fundo isso tem muito que ver com o problema do autoritarismo, entende? E eu acho que à leitura autoritária, se a nossa opção é libertária, temos que propor a Leitura Libertária, que é uma leitura da coragem de não entender o que se leu, que é a leitura do correr risco - porque, vê vem, eu não corro risco só porque eu escrevo, eu corro também quando leio porque ler é reescrever. 